\title{
EMOÇÕES, SENTIMENTOS DE NOSTALGIA E SOFRIMENTO PSÍQUICO: A DIMENSÃO DOS AFETOS NAS EXPERIÊNCIAS E MEMÓRIAS DE UMA COMUNIDADE DE MIGRANTES
}

\author{
Emotions, nostalgy feelings and psychic suffering: the dimension \\ of affects in the experiences and memories of a migrant community
}

Edmar Aparecido de Barra e Lopes*

\begin{abstract}
Resumo. O presente artigo insere-se no bojo do debate em torno dos conceitos de memória, experiência, subjetividade e suas relações com a história oral. Com base em bibliografia especializada e na análise de fontes orais de migrantes/ocupantes da ocupação Fazenda Caveirinha, no final dos anos de 1970 e início de 1980 (na região noroeste da cidade de GoiâniaGO), identificamos e buscamos compreender a manifestação de uma recorrência de temporalidades comuns às falas de depoentes perpassadas por emoções e sentimentos de nostalgia e pelo sofrimento psíquico. Assim, as falas são analisadas como universo de valores e tradições, costumes e hábitos, experimentados e rememorados cotidianamente pelos sujeitos desse movimento social enquanto dimensões constitutivas e constituídas do e no mesmo.
\end{abstract}

Palavras-chave: memória; afetos; migração; nostalgia; sofrimento.

Abstract. The following article inserts itself in the bulge of the debate concerning concepts of memory, experience, subjectivity and their relations with oral history. Based on specialised bibliography and on the analysis of oral sources of migrants/occupants of Fazenda Caiveirinha, in the late 1970s and early 1980s (in the northwest region of the city of Goiânia-GO), we identify and seek to comprehend the manifestation of a recurrence of common temporalities in the speeches of deponents pervaded by emotions and feelings of nostalgia and by psychological distress. Thus, the talks are analysed as a universe of values and traditions, customs and habits, experienced and recalled daily by the subjects of this social movement as constitutive and constituted dimensions of the movement and in it.

Keywords: memory; affections; migration; nostalgia; suffering.

Doutor em Ciências Sociais pela Universidade Estadual de Campinas (UNICAMP-SP), professor adjunto da Universidade Estadual de Goiás (UEG) e da Faculdade de Ciências Sociais (FCS) no âmbito da Universidade Federal de Goiás (UFG). Goiás - GO, Brasil. Email: ed.clio@ hotmail. com. Orcid: 0000-0001-9576-510X. 


\section{Introdução ao debate}

A postura investigativa - é sabido - pressupõe uma formação continuada. Outro pressuposto é o de que a pesquisa depende de um intransigente compromisso teórico, histórico e metodológico para compreensão da realidade social. Ao mesmo tempo, exige o constante diálogo com novas preocupações do campo profissional, no qual desenvolvemos nossa trajetória.

Para alcançarmos essas exigências, não raramente, é necessário retornarmos a determinados temas de pesquisa. Essa é a motivação que levou esse autor a retornar ao tema de pesquisa em questão, duas décadas depois. Agora, o objetivo é buscar compreender um aspecto da vida cotidiana dos sujeitos em questão que, há 20 anos atrás, não constituía um problema de pesquisa. Referimo-nos às articulações entre afetos, experiência e memória no cotidiano de migrantes internos que vivenciaram o cotidiano de luta por moradia na ocupação Fazenda Caveirinha (1979-1989)' ${ }^{1}$, na região noroeste da cidade de Goiânia-GO².

Ademais, cabe observar que o esforço representado pelo artigo em tela também se justifica em função do crescente debate e centralidade que os conceitos de memória coletiva ${ }^{3}$ e experiência têm assumido nas últimas

1 Segundo Chaves (1985), essa ocupação teve início em julho de 1979, quando cerca de 100 famílias, inicialmente, invadiram uma área da região noroeste da cidade de Goiânia. Ademais, Barra e Lopes (2008) explica que a ocupação Fazenda Caveirinha (Jardim Nova Esperança) marca a emergência de uma crescente politização das práticas das ocupações urbanas na cidade de então, o que é sugerido nos textos noticiosos de vários jornais, nos quais expressões como "organização", "direito de posse", "comissão de moradia", "assessoramento de advogados", "formas organizadas de resistência", "cidadania" e outros, multiplicam-se. Apenas a título de alguns poucos exemplos: 1) Folha de Goiás: "Goiânia com quase 5 mil invasores", 28 de janeiro de 1977; 2) Cinco de Março: "Prefeitura desaloja mais de vinte famílias", 26 de junho de 1977; 3) O Popular: "Prefeitura retira 35 famílias de invasões", 24 de outubro de 1979; Folha de Goiás: "Decreto impediu a intervenção da PM", 07 de novembro de 1979 etc. Sobre a contextualização histórica da referida ocupação, ver também Gomes (2019).

2 A retomada do tema da pesquisa em questão também resultou do retorno ao campo da mesma (a partir do primeiro semestre de 2018), na forma de conversas e reuniões com alguns dos migrantes/ocupantes, referidos nesse artigo e que esse pesquisador havia entrevistado em 1998. Sendo que esses encontros resultaram inicialmente de convite do doutorando em História, pela Universidade Federal de Goiás-UFG, Lucius Fabius Ben Jah Jacob Gomes, para conhecer projeto em fase inicial desses sujeitos - apoiado por equipe interdisciplinar - de construção do Centro de Memória Nova Esperança. Cabe observar que "Nova Esperança" é o nome do bairro que resultou da referida ocupação Fazenda Caveirinha.

3 Halbwachs (2004, p. 112, apud Souroujon, 2011, p. 4-5), explica que: "[...] podemos perfectamente decir que el individuo recuerda cuando asume el punto de vista del grupo y que la memoria del grupo se manifiesta y se realiza en la memoria individual". E acrescenta que: "[...] los recuerdos [...] no nos ponen solamente en relación con nuestro pasado, sino que nos relacionan con una época, nos reubican en un estado de la sociedad en donde existen alrededor de nosotros, muchos otros vestigios de aquello que descubrimos en nosotros mismos". Nessa perspectiva, Da Costa e Maciel (2009, apud Da Costa, De Castro e Silva, 2015, p. 287), explicam que "A memória coletiva [grifo nosso] é sempre um projeto inclusivo. Em sua construção cabem diferentes narrativas e interpretações, familiaridades e estranhamentos, congruências e 
décadas nas ciências humanas, em particular, no que concerne aos estudos migratórios.

Nessa linha, a discussão sobre o legado da história oral ${ }^{4}$, em especial para a renovação dos últimos, ainda é algo em construção. Convicto de que os movimentos sociais não devem ser esvaziados de suas experiências significativas protagonizadas pelos seus sujeitos e do ponto de vista desses ${ }^{5}$, nessa análise conferimos papel privilegiado às categorias em questão, uma vez que pretendemos compreender a importância da dimensão dos afetos ${ }^{6}$ no processo de construção de novas formas de sociabilidade política no âmbito da comunidade ${ }^{7}$ considerada.

\section{Metodologia e análise de dados}

Para alcançarmos esse objetivo, analisamos (com base na história oral) depoimentos concedidos por indivíduos que protagonizaram tal movimento social. Narrativas permeadas por emoções ${ }^{8}$ que atravessam as temporalidades

distensões, agonismos e antagonismos. A memória coletiva, nesse caso, constituir-se-ia a partir da necessária diversidade que caracteriza o grupo". No mesmo sentido, esclarecem que "(...) os afetos aglutinadores e as memórias coletivas de uma comunidade se organizam em torno do que existe em comum na heterogeneidade".

4 Conforme Thompson (1992, p. 338), a história oral é uma ferramenta metodológica importante no acesso à memória coletiva, uma vez que a mesma "permite devolver a história às pessoas em suas próprias palavras. E, ao dar-Ihes um passado, ajuda-as também a caminhar para um futuro construído por elas mesmas".

5 Na linha de linha de autores como Sawaia (2002), Montero (2007), Ghon (2010) e Ariza (2016).

6 De acordo com Deleuze (2002, p. 56 apud Barreiro et alii, 2018), a categoria, "afecção remete a um estado do corpo afetado e implica a presença do corpo afetante, ao passo que o afeto remete à transição de um estado a outro, tendo em conta variação correlativa dos corpos afetantes. (...) Dessa forma, os afetos (alegria/tristeza) dizem respeito a estarmos sujeitos aos aumentos e também diminuições de nossa potência de agir" (Deleuze, 1978). Acrescentando que: "(...) os afetos que mobilizam um grupo se definem pelas forças de coesão e difusão, que aglutinam tensionam e reorganizam coletivos. A partir de situações, fenômenos e eventos que produzem diferentes sentidos de integração entre seus membros (...)". Nesse sentido, “(...) uma comunidade produz ora mais ora menos afetos aglutinadores, apoiados tanto em sentimentos de pertença e cumplicidade, construindo experiências de solidariedade, quanto em sentimentos de divergência, tensionando e buscando, de forma mais ou menos bélica, campos possíveis de negociação" (Da Costa, De Castro e Silva, 2015, p. 287).

7 Conforme Da Costa e Maciel (2009, p. 5), Tönnies (1957) é reconhecido como: “(...) o fundador da teoria da comunidade. Ele apresentou os retratos ideais típicos dessa forma de associação social, oferecendo um estudo de contrastes entre a natureza solidarística de relações sociais na comunidade e as relações em grande escala e impessoais nas sociedades industrializadas". Acrescenta que Tönnies, na mesma obra, “(...) introduziu o dualismo 'sociedade (Gemeinschaft)/ comunidade (Gessellschaft)' no discurso científico contemporâneo". E ainda que ele "(...) propõe que o conceito de sociedade corresponda à vontade consciente e nascida do arbítrio dos respectivos membros, enquanto o de comunidade corresponderia a uma vontade essencial ou orgânica".

8 Ariza (2016) explica-nos que: a emoção é uma propriedade da interação social indissociável do contexto em que se produz; que as emoções são consequências das propriedades estruturais da interação social e se encontram ancoradas nas situações em que emergem; que proporcionam 
da família e da casa, do trabalho e das festa ${ }^{9}$ e compreendidas como campos de experiências cotidianas dos migrantes referidos(as), constitutivas e constituídas de e por: afetos e memórias individuais e coletivas; tramas e desentendimentos; alianças e constrangimentos; conflitos e negociações.

Destacando também que entendemos essas temporalidades do cotidiano desses migrantes como instituintes e instituídas de e por um sentido de comunidade, como encontramos em Mcmillan y Chavis (1986) e Montero (2007). Sendo que, nessa linha, cabe destacar que a opção por tal caminho teórico-metodológico implica em um diálogo necessário entre a produção de depoimentos orais, tomados enquanto saberes práticos - incorporados - de classe (Ferreira, 2012), e suas articulações (no âmbito dessa opção teóricometodológica) com categorias, tais como: memória individual e memória coletiva; experiência e cotidiano; afetos e sentimentos ${ }^{10}$.

Esforço que desenvolveremos ao problematizarmos a fala de cada um dos/as três depoentes ${ }^{11}$ selecionados a partir de 14 entrevistas realizadas inicial e presencialmente em julho de 1998, na cidade de Goiânia-GO, no bairro

aos atores elementos interpretativos para enfrentar e responder a diversos contextos situacionais; que, assim que uma emoção emerge, resulta imperativo conhecer o locus da mesma para melhor compreendê-la, uma vez que os afetos ocorrem numa localização espaço-temporal e marcadas por relações de poder que constituem e são constituídas por relações sociais desiguais.

9 Não é nosso objetivo explorar a ampla literatura especializada da antropologia sobre memória e emoções (seja clássica ou mais contemporânea). Entretanto, é oportuno pelo menos citar trabalhos como os de Das (1999, 2011), que analisa a dimensão da narração de experiências pessoais traumáticas, além de outros como, por exemplo, Lutz e White (1986), Rezende e Coelho (2010), Goodwin, Jasper e Polleta (2001), Hoggett e Thompson (2012).

${ }^{10} \mathrm{O}$ que implica em admitirmos como pressupostos, tal como defende Araújo Vieira e Khoury (1992, p. 105-106), que: “(...) o movimento social é construído pelos sujeitos em ação, a partir do modo como [compreendem] sua função na realidade social e a sua própria função nele (...). A trajetória individual dos sujeitos ilumina uma dimensão dos fatos coletivos, e a experiência realiza-se tanto a partir de escolhas racionais, como de emoções, valores, aspirações (...). $\mathrm{Na}$ coleta de depoimentos individuais, o pesquisador deve atentar para a influência que a experiência presente exerce sobre a narração do sujeito (...) [ainda] o lembrar não é somente reviver o passado ou recuperá-lo, mas reconstruí-lo, repensá-lo com imagens e ideias do presente (...). [Na prática] de história oral (...) entrevistador e entrevistado tornam-se atores de uma mesma experiência (...). [A necessidade de termos clareza de que o] documento assim produzido [implica na] impossibilidade de ignorar o elemento memória, ou seja, a atribuição de significados que o depoente acrescenta a sua experiência social, assim como o entrevistador, ao escutar a narrativa e ao sistematizá-la (...)".

11 Os depoentes referidos são: 1) Maria de Jesus Rodrigues - 46 anos à época da entrevista, exmutirante, migrante, membro da Associação de Moradores do Jardim Nova Esperança, criadora do grupo de teatro popular Alma Nova. Fragmento de entrevista que foi realizada em julho de 1998 e revisitado para a finalidade do artigo em tela; 2) Olavo Novais Alves - 63 anos à época da entrevista, migrante e ex-mutirante, atualmente é vigia noturno e balconista. Fragmento de entrevista que foi realizada em julho de 1998 e revisitado para a finalidade do artigo em tela e; 3) Maria Ferreira de Souza - 46 anos à época da entrevista, migrante, ex-mutirante, mãe de 6 filhos, natural de Pirenópolis-Goiás, ex-trabalhadora de fazendas do interior de Goiás e proveniente de uma família de 11 pessoas. Fragmento de entrevista que foi realizada em julho de 1998 e revisitado para a finalidade do artigo em tela. 
Nova Esperança, antes denominado ocupação Fazenda Caveirinha. Exercício realizado, por sua vez, no segundo semestre de 2018. A partir dessa nova preocupação, houve o estímulo à releitura e revisão das entrevistas referidas. Ademais, cabe observar que a escolha desses três casos se deu em função de serem muito expressivas no que concerne ao objeto do artigo em tela e por encontrarem-se nos limites formais impostos pela natureza dessa forma publicação.

Cabe esclarecer também que todas as entrevistas foram produzidas a partir de questões semi-dirigidas que orientaram a produção das entrevistas. A seleção dos(as) entrevistados(as) foi orientada por uma pesquisa exploratória e, a partir daí, foram agendadas as 4 entrevistas iniciais. Após a realização de cada uma dessas entrevistas, com base no procedimento bola de neve (snow ball), foram solicitadas sugestões de novos indivíduos com quem poderíamos conversar, até produzirmos os referidos depoimentos.

Os referidos tiveram duração média de 42 minutos. Sendo que as três entrevistas, objeto dessa análise, tiveram, respectivamente, a duração de 1 hora e 28 minutos, 42 minutos e 1 horas e 40 minutos. As transcrições foram realizadas e digitadas nos meses de setembro, outubro, novembro e dezembro no mesmo ano de realização das mesmas e pelo próprio autor. Optamos em manter as falas como ditas, seguindo sempre de perto orientações colocadas pela opção teórico-metodológica escolhida, como encontramos ricamente em Tourtier-Bonazzi (1998).

\section{Algumas questões referentes à memória, à experiência e aos afetos}

Uma das principais preocupações nesse momento do artigo é a de tentar compreender algumas questões referentes à memória ou ao ato de rememorar perpassado por afetos na experiência dos migrantes em questão. Acrescentando que a afetividade ${ }^{12}$ dos atores é revelada nos adjetivos usados, de tal modo que, nos processos de rememoração, observamos marcas identitárias e de constituição do sujeito nas inter-relações entre passado e presente.

As articulações entre migrações e emoções dizem respeito às marcas que tal experiência imprime na vivência emocional desses sujeitos e seus efeitos impactam as estruturas afetivas e relações familiares dos mesmos, além

\footnotetext{
${ }^{12}$ Nesse artigo, como encontramos em Gonçalves (2018, p. 91), “(...) Os sentidos de afeto (...) se processam de maneira aberta". Por vezes, [nos referimos] "(...) a afeto enquanto afecção, capacidade de ser tocado e tocar algo-alguém-situação, que estimula a movimentação de percepções, provoca memórias. Também quer dizer afeto a movimentação de emoções e sentimentos, enquanto apreciação e explicação para as situações vividas entre os órgãos do sentido e os sentidos que se constroem a partir do toque na realidade. O contexto em que a palavra aparece indicará a qualidade, que se espera salientar a cada momento".
} 
de atuarem sobre a dinâmica das tensões resultantes dos conflitos entre as estruturas normativas da sociedade de origem e a sociedade de destino desses.

A compreensão dessa dimensão é imprescindível para a análise do processo de ocupação e luta por moradia ocorrido na Fazenda Caveirinha (especialmente entre 1979 e 1989), na região noroeste da cidade de Goiânia-GO, enquanto um universo de experiências socialmente compartilhadas/vivenciados e por meio das quais identidades individuais são reelaboradas.

Trata-se de reconhecer as narrativas desses migrantes, enquanto compósito no qual se sobressai estados afetivos variados, tais como: a dor e a tristeza, a culpa e o orgulho, a humilhação e o ressentimento, a nostalgia ${ }^{13}$ e o sentimento ${ }^{14}$ de perda em relação ao lugar de origem, entre outros. A partir desse movimento, buscamos apanhar: a) o processo de construção da memória individual; b) a construção da memória coletiva como constante vir a ser e c) o papel que tais "experiências" desempenham na construção da história do espaço urbano em Goiânia enquanto sociedade de destino dos migrantes. Como lembra Scott (1998), a análise dessas experiências contribui para questionar entendimentos históricos convencionais que tendem a se configurar como representação autorizada do real.

Sobre a noção de experiência, cumpre mencionar a análise segundo a qual ela:

(...) une ideias de influências externas e sentimentos subjetivos, o estrutural e o psicológico. [Conferindo] ao conceito uma influência mediadora entre a estrutura social e a consciência social [;] (...) significa o ser social, especialmente os domínios afetivos da família e da religião, e as dimensões simbólicas de expressão. (...) [definição que] separou o afetivo e o simbólico do econômico e do racional. [Uma vez que para esse autor] (...) as pessoas

${ }^{13}$ De acordo com Albuquerque Jr. (2013, p. 153): “A saudade, como todo sentimento, implica a elaboração de uma linguagem que a expresse, implica a escolha, a eleição de gestos, de enunciados, de mímicas, de performances, de imagens, de ações e reações que the deem materialidade, realidade e espessura social e histórica. À saudade não basta ser sentida para existir, ela deve ser, antes de tudo, conceituada como tal, deve ser nomeada, chamada de saudade e materializada em gestos, ações, reações, performances".

${ }^{14}$ De acordo com Hirai (2014), para o crítico literário marxista Raymond Williams (1977) existem duas tendências dominantes na análise e na descrição objetivista da cultura e da sociedade. A primeira é que cultura e sociedade não são compreendidas ou descritas como o que está em processo de formação no presente, mas como o que já foi formado, portanto, como produtos que pertencem ao passado. A segunda tendência é que o pensamento, a ideologia, a visão de mundo e a crença sejam compreendidos e descritos como "sociais", como o que já foi formado e oposto à consciência, experiência e sentimentos. Sendo que esse autor, para sair dessas tendências de análise sociocultural que não permitem entender a tensão e a articulação entre o social e o pessoal, e analisar e descrever o processo de formação sociocultural, propõe o conceito de "estrutura de sentimento". Destacando que esse conceito enfoca a fase logo antes de aparecer alguma estrutura formada, uma fase intermediária do processo em que sentimentos, consciências, experiências e personalidades tornam-se uma nova estrutura social. 
não experimentam suas próprias experiências apenas como ideias no âmbito do pensamento e de seus procedimentos (...) [;] (...) elas também experimentam suas experiências como sentimento (...). [E estes] (...) são 'manipulados' culturalmente como normas, obrigações familiares e de parentesco e reciprocidades ou (através de formas mais elaboradas) na arte ou nas crenças religiosas. [Sendo que ao] (...) mesmo tempo, procede de algum modo essas formas de expressão e assim permite um escape de uma determinação estrutural forte: 'para qualquer geração, em qualquer agora'. [Acrescentando que] (...) os modos pelos quais ela manipula a experiência desafia a previsão e foge a qualquer definição estreita da determinação. (Thompson, 1981, p. 171 apud Scott, 1998, p. 297-327)

Nos depoimentos dessas pessoas, um passado determinado (suas vivências anteriores ao cotidiano de ocupação e luta por moradia na Fazenda Caveirinha) é revisitado de forma duplamente condicionada, ou seja, marcado por uma dinâmica do processo de rememoração que é, ao mesmo tempo, individual e partilhada.

As lembranças dessa experiência, como demonstram várias entrevistas, revelam uma dinâmica psicossocial em que, ao recordar, essas pessoas pensam, rearticulam suas trajetórias de vida para o outro e para si mesmas. De acordo com Da Costa e De Castro e Silva (2015), apoiadas em sentimentos de pertença e cumplicidade, sentimentos de divergência, quanto experiências de solidariedade, essas pessoas buscam, de forma mais ou menos bélica, campos possíveis de negociação.

É nesse sentido que Maria Ferreira de Souza, ao ser perguntada a respeito do clima de insegurança na Fazenda Caveirinha, assim lembrado por muitos migrantes nos primeiros anos da ocupação, diz o seguinte:

(...) Logo que eu cheguei por aqui, eu não fiz barraca, eu fiz um cômodo só de alvenaria. Mas esse cômodo desmoronô com a chuva de vento que deu. Nesses lugá, toda vida dá chuva de vento, né? Eu não sei o que tem, toda a vida dá... No meu modo de pensá, que eu acho errado, esse negócio de invasão, eu acho que isso não tá na presença de Deus, porque dono da terra todos nós somos, porque Deus deixô a terra prá todos nóis. Mas nóis devemos respeitá o direito dos otros. Ninguém deveria entrá aqui, porque, na palavra de Deus, tá escrito: merece castigo todo aquele que não respeitá a parte do outro. Então, todo lugá que o pessoal forma assim, esse tipo de invasão, é... são lugares assim, muito assim ... Parece que num limpa nunca (...).

A escolha deste fragmento do depoimento de Maria Ferreira de Souza foi feita porque ajuda a compreender os significados da atividade de rememoração e o papel que ela desempenha ao conferir maior visibilidade a determinados processos, práticas, mentalidades e o modo como as emoções são também parte estruturante das mesmas. Demonstrando como não apenas o lugar de origem, mas também o lugar de destino, o processo de adaptação constitui-se de eventos carregados de sentimentos na vida familiar 
e comunitária, inclusive sofrimento psíquico sob a forma de culpa (Lara, 2016), como constatamos na narrativa acima.

Nessa fala, a depoente costura relações com aspectos de sua experiência vivida anteriormente à sua participação na ocupação da Fazenda Caveirinha. O depoimento articula-se com o tempo do trabalho na roça, quando criança. Ao tempo, além da lida diária no campo, o trabalho da mesma enquanto mulher com responsabilidades para com o marido e filhos. Ela fala das chuvas de vento constantes na época da ocupação como um castigo de Deus, pelo fato de área ter sido, segundo a mesma, 'invadida'. E ressalta: “(...) eu mesmo não invadi. A gente aqui comprô o direito. Mas eu (...) veio pensá qui, se tivesse comprado esse direito prá outra parte, era melhor". De outro, rememora uma experiência que alimenta um processo de sofrimento psíquico (culpa) ao mesmo tempo reforçando a complexidade do fenômeno das migrações e o papel que as emoções desempenham nela.

Quando Maria Ferreira de Souza diz: “(...) na palavra de Deus tá escrito: merece castigo todo aquele que não respeitá a parte do outro $(. . .)^{\prime \prime}$, ela nos leva a pensar sobre como dadas crenças religiosas estão presentes nas formas como os indivíduos vivem suas próprias experiências e sobre como as mesmas participam na dinâmica do sofrimento psíquico configurado enquanto sentimento de culpa. Isso também nos permite compreender melhor como esse tipo de mentalidade ajuda a sustentar práticas e estruturas de exploração no campo e na cidade ao mesmo tempo indissociáveis e determinantes do contexto marcado por relações sociais desiguais em que se produz os sentimentos, em geral, e a culpa, em particular.

Nas relações existentes entre a reprodução de determinadas estruturas de poder no campo e na cidade no que concerne à propriedade do solo rural ou urbano, esse tipo de mentalidade e o sofrimento psíquico em questão, como observamos, é um dos principais traços do processo de migração em tela na subjetividade da depoente. O que também se encontra traduzido pelo depoimento de Maria Ferreira de Souza quando essa - apesar de sua condição de migrante/ocupante da ocupação Fazenda Caveirinha - em outro momento da narrativa, complementa:

(...) Seja lá do jeito que fô, eu sô contra invadição, sô contra mesmo, sô contra invadição. Sô contra a qualqué pessoa entra na propriedade do outro. Agora esses grandes aí deveria fazê uma coisa mais bem feita, prá que todo mundo tivesse a oportunidade de ter o seu cantinho, limpo, honesto.

A forma como a depoente se posiciona ao ser indagada sobre a ocupação 'invadição', reafirma na constituição de sua visão de mundo valores rurais ainda muito fortes, que persistem e contribuem para nortear suas práticas perante os desafios colocados na luta pela sobrevivência no universo urbano. 
Além do mais, quando Maria Ferreira de Souza diz: “(...) esses grandes aí deveria fazê uma coisa mais bem feita, prá que todo mundo tivesse a oportunidade de ter o seu cantinho, limpo, honesto", é possível notar um esforço da depoente em lidar com a contradição provocada e alimentada, de um lado, por valores apreendidos como verdades acabadas desde sua infância rural e, de outro, sentimento angustiante de dar respostas a questões básicas para a garantia de sua sobrevivência e de seus familiares. Um esforço, entretanto, orientado pela ideia de que qualquer mudança histórica nesse sentido deva passar - antes de tudo - pela boa vontade das elites dominantes.

O fundamental deste depoimento para a análise está em nos permitir compreender que a própria ocupação constitui ao mesmo tempo um espaço diversamente praticado e atravessado por profundas tensões sociais e, ao mesmo tempo, subjetivas. Ademais, devemos lembrar que a necessidade de morar figura como motivação e fundamento psicossocial a partir do qual esses migrantes/ocupantes desenvolvem um forte sentimento de solidariedade e pertencimento enquanto atores dessa luta. Esses elementos nos chamam atenção para a complexidade constitutiva da identidade dos mesmos.

Nessa linha, Thompson (1998, p. 283), no desenvolvimento de uma pesquisa, concluiu: “(...) Ao invés de supor que as vidas e as memórias da classe trabalhadora necessariamente iriam desmascarar as poderosas memórias nacionais, (começou) a perceber as contradições das vidas que se apresentavam a favor e contra às formações culturais dominantes".

É possível dizer algo semelhante sobre o significado do depoimento de Maria Ferreira de Souza, especialmente quando consideradas as demais entrevistas que aqui exploramos. Por meio desse relato, acordamos para o fato de que a ocupação Fazenda Caveirinha, sob pena de ser mitificada, não pode deixar de ser tomada como espaço diversamente experimentado ${ }^{15}$. Isso ocorre de tal forma que, durante a fala, constata-se consciente esforço da entrevistada objetivando equilibrar sentimentos e emoções num quadro de rememoração marcado pela tensão psíquica.

A partir de tais apontamentos, pode-se dizer que o depoimento de Maria Ferreira de Souza foi uma fala que destoou da maneira como a maioria dos depoentes interpreta os significados do movimento. A singularidade da narrativa dessa depoente está no fato de que sua relação com aquele espaço era singular no sentido de traduzir uma negação relativa à forma como esse território fora histórica e coletivamente apropriado pela comunidade. Esse

\footnotetext{
${ }^{15}$ No sentido atentarmos para tal possibilidade de infundada interpretação, buscamos Portelli (1997, p. 16), quando este esclarece: "A História Oral tende a representar a realidade não tanto como um tabuleiro em que todos os quadrados são iguais, mas como um mosaico ou colcha de retalhos, em que os pedaços são diferentes, porém, formam um todo coerente depois de reunidos".
} 
depoimento revela uma identidade que, apesar de estar articulada com o processo de ocupação, ao mesmo tempo, expressa desconforto em fazer parte do mesmo.

A relação de Maria Ferreira de Souza com o cotidiano de luta por moradia em questão nunca possuiu o sentido orgânico que teve para outros indivíduos desse movimento social ${ }^{16}$. Isso ajuda a entender melhor a forma plural como cada uma dessas identidades tende a praticar e/ou resignificar tal espaço. No âmbito de tal consideração, destacamos, de um lado, a seguinte afirmação dessa depoente: "(...) invadição é algo que não está na presença de Deus", ao passo em que, de outro lado e sobre o mesmo tema, outra depoente - Maria de Jesus Rodrigues - afirma que a ocupação é: “(...) uma coisa determinada do alto, uma coisa determinada por Deus". A narrativa da última, diferente da primeira, configura-se de forma atravessada não por sofrimento psíquico sob a forma de culpa, mas por um forte sentimento de orgulho e fé.

\section{Os tempos da família e da casa}

À medida que as entrevistas eram realizadas, os depoimentos gradualmente apontavam para a forte presença de migrantes de várias zonas rurais, principalmente, do interior de Goiás, na ocupação. Também era possível constatar uma forte presença da família nas 14 entrevistas referidas, inclusive essas três estudadas agora. Esses elementos foram examinados com refinamento em trabalhos como os de Lucena (1997) e Santana (1998). Essa constante recorrência nas falas em relação ao tempo da infância na roça, descrito como tempo do trabalho (mas não apenas) pode ser explicada, em certa medida, quando atentamos para o fato de que, no Brasil rural, o trabalho agrícola sempre foi fortemente marcado pela atividade familiar (Durham, 1973).

Essa realidade, associada ao passado rural da maioria dos depoentes, ajuda a compreender por que as narrativas, mesmo quando provocadas por questões que aparentemente diziam respeito apenas ao momento e espaço de realização das mesmas ${ }^{17}$, são, em sua maior parte, crivadas por lembranças de múltiplos aspectos das relações da narradora com a temporalidade da família, quando de sua vida num passado não distante, ou seja, no campo. Nesse sentido, Maria Ferreira de Souza, sobre a estrutura de sua família, diz: “(...) olhá irmão legitímo mesmo, nós somos 14, são sete homens e sete

${ }^{16}$ Como é o caso de Maria de Jesus. A ligação orgânica dessa mulher com o movimento em questão contribuiu para que a mesma conferisse à ocupação da Fazenda Caveirinha significados distintos daqueles atribuídos por Maria Ferreira de Souza nos quais, por exemplo, está ausente o sentimento de culpa e medo.

17 Julho de 1998, ocupação Fazenda Caveirinha, atual Jardim Nova Esperança (residência da depoente), na cidade de Goiânia. 
mulheres, mais é que minha mãe mais meu pai, pegô otos dos otos prá criá, porque uma veis morreu um pai e uma mãe e ficô cinco filho abandonado (...). Completô, completô dezenove".

De outro modo, no mesmo sentido de Lara (2016), observamos que a experiência do processo de migração subjetivamente apresenta uma natureza parcial e inconclusa, reaberta e reelaborada de forma permanente a partir de eventos cotidianos e por diferentes vias. Um processo caracterizado por uma dinâmica de emoções na qual se manifesta complexas combinações de sentimentos e que podem - embora não necessariamente - ser muito dolorosos.

Ao longo das entrevistas, a casa na roça aparece como centro de imagens de um passado, ora lembrado de forma dolorosa, ora lembrado com um sentimento de nostalgia. A casa na roça aparece também como porta de entrada para um sem número de atributos positivos conferidos pelos narradores ao mundo rural de origem (perdido) e que tendem a mitificá-lo como forma - inclusive - de reelaborar tal perda. Nesse sentido, quando Maria Ferreira de Souza é convidada a falar um pouco sobre a sua casa na roça, ou seja, das lembranças que essa Ihe traz, ela nos diz:

Olha, a casa minha, que nós morava, eu tenho muita saudade dela, mais ao mesmo tempo instante não, porque no interior, quando nós fomos crescendo, fomo estudando, não tinha emprego, naquela cidade não tinha emprego. Se não fosse a lavoura, a gente não tinha mais nada. Era muita pequena (a cidade). Quando surgia a política, o emprego lá não dava nem pá família dos candidatos, quanto mais prá nóis, né? Então, não deixa muita saudade, por esse fato que a gente teve que saí de lá (olhos lacrimejando). Gostava da casa e tudo, mas, mas não tinha condições da sobrevivência dentro daquela casa, se não fosse a lavoura. Da lavoura foi ficando difícil. Conforme falei pro senhor, os fazendeiros na região foi plantá cana, porque abriram uma Próàlcool lá, aí já não usava mais prantá mais nada, era só cana. Então aquela cana dava um emprego, mas não dava prá todo mundo. Ficô muita gente na cidade desempregada. Então, as pessoas que tavam naquele local teriam que saí daquele, daquele local. Inclusive nóis mesmo saímo e ficamo oito ano sem vendê a casa, porque ia vendê ela, ela não tinha valor prá comprá em outro lugar. Então essa casa ficô prá lá abandonada(...). Por final, quando minha mãe vendeu essa casa, com o valor dessa casa, ela fez uma área aqui em Goiânia. Uma arinha rui, prá você vê o quanto não tem valor.

Percebemos, associadas às reminiscências de Maria Ferreira de Souza sobre sua infância na casa da roça, imagens de um passado fortemente marcado pelo trabalho na lavoura. Apesar do trabalho "duro" na roça reconhecido pela narradora, é recorrente na sua fala o sentimento de nostalgia não apenas como sentimento que evoca emoções associadas ao lugar de origem, mas também que contribui para a construção de atitudes relacionadas às práticas socioculturais inerentes ao processo de migração, tal como a adaptação ao 
lugar de chegada (Hirai, 2014). O sentimento de nostalgia combinado ao de orgulho também figura vinculado à ideia de "fartura" enquanto elemento de reelaboração do sofrimento derivado da ruptura com o lugar de origem. Nesse sentido, a depoente lembra:

(...) era tempo muito bom, com muita fartura, uma fartura que ninguém sabia o que era necessidade (...). A fartura que eu falo prá você, é que lá agente nunca conheceu nada aos quilo, como nóis (...) compramo na cidade, sê busca um quilo de carne, sê busca um quilo disso, um litro de óleo e naquele tempo nóis não usava esse negócio, agente - por pobre que a pessoas era ele podia mata uma vaca. O meu pai matava uma vaca, então o dia que ele matava uma vaca, era uma fartura: lata cheia, salgava carne, punha aquela carne de sol, punha carne de lata, fazia aquelas almôndega, bem gostosa. Então aquele tempo era muito bom, era uma fartura e era pobre, né.

Entretanto, o tempo da casa na roça enquanto tempo de "fartura" não impede a emergência reconfigurada do sofrimento psíquico resultante do reconhecimento desse também como tempo de muita dificuldade e privação. Constatamos isso, por exemplo, quando a depoente rememora que, para ela e sua família, a luta pela sobrevivência tornava-se cada vez mais difícil em função da dificuldade de a família encontrar emprego na lavoura no município do arraial de São Francisco-GO, onde morava. A vivência do espaço da casa da roça é lembrada como território fortemente nucleado pela família da depoente, assim como sua vizinhança: o arraial de São Francisco-GO, o qual era esporadicamente visitado, especialmente em datas festivas, ou seja, em dias de missa ou de feira.

A casa que figura inicialmente como lugar de acolhimento e proteção, gradualmente, passa a ser narrada como território de carências. De outro modo, o tempo da casa - nessa passagem - é experimentado como articulação entre o desejo e o sofrimento, a partir das relações que se estabelecem entre o cotidiano e a subjetividade dessa migrante.

Ao falar do espaço da casa na roça durante sua infância e, por conseguinte, de sua família, novamente o sentimento de nostalgia prevalece na narrativa da depoente. Ela fala desse tempo como uma época marcada por outra ética reguladora das relações socais. E na qual os laços de vizinhança aparecem como um indício forte desse aspecto da prática do espaço familiar. Neste sentido a depoente diz:

(...) então quando eu alembro desse tempo que ficô muitos anos atrás, eu alembro com saudade, né, da humildade de todo mundo, da sinceridade, do desejar o bem para o próximo, que (...) acabô. (...) Eu não trocaria nunca a vida da fazenda pela cidade, eu tô aqui porque em todos os casos não tem outro jeito, tem que viver é aqui né. 
O tempo da casa na roça é diversa e conflituosamente rememorado, ou seja, o tempo de "fartura" transforma-se em tempo de sofrimento, dificuldade para sobreviver. Isto é facilmente notado quando a depoente afirma num primeiro momento: "(...) olha a casa minha, que nóis morava, eu tenho muita saudade dela, mas ao mesmo instante, não (...)". Mas, por que a casa/família, enquanto núcleo de memória, é diversamente experimentada no momento (julho de 1998) em que a entrevista fora realizada? Isso acontece, como já foi anteriormente fundamentado por Portelli (1997), Thomson $(1997,1998)$ e Thompson (1991), porque, ao narrar, o indivíduo reelabora aquilo que ele pensa de si próprio e do espaço quotidianamente praticado por ele. No caso em questão, a trajetória da migrante entre o lugar de origem e o lugar de destino (ocupação Fazenda Caveirinha), implicou num itinerário subjetivo do qual resulta a nostalgia enquanto sentimento amplamente marcado por distintas emoções (Alexandroff, 2012), como acabamos de constatar.

Outro referencial de memória importante para a compreensão das diversas temporalidades que se cruzam na caracterização do presente citadino dessa ocupação e que, simultaneamente, confere maior visibilidade à natureza das flexíveis fronteiras entre o rural e o urbano, é o mundo do trabalho na roça. Vejamos como ele é rememorado nas narrativas que seguem.

\section{Os tempos do trabalho e das festas}

À medida que os depoentes em tela rememoram o tempo do trabalho, pode-se perceber a ascensão de um conjunto de representações sempre referidas ao trato com a terra e representativas de dimensões constitutivas de múltiplas formas de sociabilidades do mundo rural. Essas falas sobre o trabalho na roça, não raramente, afiguram-se como narrativas fronteiriças entre os tempos das festas, da família, das rezas e da natureza (das chuvas, da seca etc.). Podendo ser investigadas como uma ponte que facilita ou pode facilitar a apreensão de uma diversidade de formas de relações sociais dinâmicas que Ihes oferecem pistas sobre as temporalidades do lugar. Neste sentido, Michel de Certeau (1994, p. 200) lembra que: “(...) todo relato é um relato de viagem, uma prática do espaço (...), tem a ver com as táticas cotidianas, faz parte delas".

Essas narrativas sobre o trabalho no meio rural ${ }^{18}$ (lugar origem dos mesmos) abrem, ainda, janelas que conferem maior visibilidade à maneira como os depoentes situam-se nesse processo de rememoração,

\footnotetext{
18 Thompson (1998) defende que tal diferenciação entre campo e cidade, pode ser percebida, por exemplo, através do uso do tempo. De outro modo, no meio rural, o tempo cumpre função mediadora das relações horizontais estabelecidas de trabalho com a natureza, animais e a sociedade, pois o "relógio diário" é o dos animais e das plantas. E a rotina das tarefas pastoris, o cultivo do campo. Ou ainda, o tempo é fundamentalmente a sucessão dessas tarefas e a relação entre as mesmas.
} 
desenvolvendo uma dinâmica subjetiva onde a nostalgia se configura caracterizada por um contraste de representações entre campo e cidade que reforça a importância que esses migrantes atribuírem à localidade de origem. Constatação fundamental para compreendermos melhor os vínculos gerados por esses no lugar de chegada e residência (Glick-Schiller, 2008). Nessa linha, o migrante Olavo Novais Alves, ao contar sobre a luta pela sobrevivência na roça, nos diz:

(...) Na roça, o trabalho não dá muita oportunidade. O povo na roça tem prazo poco prá festá. (...) na roça, na época da chuva, então de acordo com a época, a roçação de pasto, ela é na época de chuva, mas passô a chuva, que vem o tempo da seca, aí, já começa as colheita, né? Aí, dá tempo de fazê festa. Então, na roça, é um lugá que o pessoal é muito assim, dia santeiro. Na roça não se fala feriado, feriado é mais na cidade, né? O tempo da seca é as festas junina, né? As festas junina tem um tempo determinado, né? O tempo da seca. As festas junina são: São Pedro, Santo Antônio, São João, São Pedro. Agora, quanto às festas do meio do ano, tempo chuvoso (...). É tempo chuvoso. Quanto ao problema do trabalho, na seca tem que aprepara a terra. (...) prá prantá o milho, o milho tá todo seco, o milho tá todo seco e quando chove, chove com a pranta seca no pé. Com o arroz já é um poco diferente, o arroz pranta no molhado, pranta quando tá bem molhado. Agora capiná, por exemplo, a gente capina o arroz quando tivé de sol, que é pro mato morrê, porque tano choveno, se a gente capiná o arroz o mato não morre. Então, a vida na roça é por aí. (...) Tempo de chuva dá prá fazê umas coisa e otras num dá.

Nesse depoimento, há dois aspectos que não podem deixar de ser ressaltados devido à expressividade que assumem durante toda a entrevista. Trata-se, em primeiro lugar, das articulações entre o tempo do trabalho na roça e o tempo da natureza. Em segundo, das relações entre o primeiro com a temporalidade das festas. Ao falar sobre o trabalho na roça, o depoente faz uma associação imediata dessa esfera da vida cotidiana com o tempo das festas e com o tempo da natureza. Trata-se de algo que se repete com frequência na fala de outros migrantes protagonistas da ocupação Fazenda Caveirinha. De modo a reforçar o sentimento de nostalgia relativa ao tempo do trabalho na roça - não raramente mitificado nessa dinâmica subjetiva marcada pela vulnerabilidade, e que aponta também para a dificuldade de adaptação ao lugar de residência/chegada, alimentada pelas perdas ou afastamento de suas referências fundadoras (Becker, Borges, 2015).

Essa constatação suscita a necessidade de nos debruçarmos um pouco mais sobre a entrevista produzida com Olavo Novais Alves, em julho de 1998, analisando nela interfaces existentes entre o processo de rememoração do tempo do trabalho na roça e a maneira como isso já estava presente na sua forma de vivenciar essa temporalidade no Jardim Nova Esperança (originalmente Ocupação Fazenda Caveirinha). 
O depoente lamenta, em vários momentos, as dificuldades para viver na cidade e a saudade dos 'tempos de roça'. A opção em trabalhar durante o dia em um pequeno boteco de sua propriedade, no bairro Jardim Nova Esperança, sugere uma alternativa para complementar o 'sustento' e, ao mesmo tempo, resistência em se adequar ao ritmo temporal do mercado ${ }^{19}$, já que o 'boteco' não aparece para o depoente apenas como lugar de trabalho, mas também lugar de lazer e de reviver o passado com os amigos e que parece funcionar como uma estratégia de enfrentamento do tipo socia ${ }^{20}$ no processo de adaptação vivenciado. Emergem também, em certos momentos de sua entrevista, fortes articulações do tempo da natureza com os dias santeiros (festas religiosas) e os de trabalhar a terra. Assim, temos:

(...) A roçação de pasto, ela é na época de chuva (...). Passô a chuva, (...) aí vem o tempo da seca, aí já começa as colheita né, aí dá tempo de fazê festa. O tempo da seca é as festas junina, né? Na seca tem que aprepara a terra, prepara a terra prá prantá o milho (...). Tempo de chuva da prá fazê umas coisa e otras num dá.

Essas reminiscências indicam um ritmo de produção do social e do político, do econômico e do cultural, nos quais os fluxos temporais do dia e da noite, da chuva e do sol, afetam de forma mais perturbadora do que o denominado tempo do relógio, as permanências constitutivas do compósito das relações e condições sociais de produção desse universo. Por um lado, a narrativa sugere formas e relações produtivas muito vulneráveis ao tempo natural. De outro lado, as mesmas se situam no bojo de um processo marcado por profundas transformações estruturais no campo no contexto do final dos anos de 1950 e início de 1960.

Nesse quadro, marcado pela imposição de novas formas capitalistas de uso da terra, segundo Martins (1975, p. 78), acentua-se a tendência de o

${ }^{19}$ De acordo com Silva (2008, p. 65): “(...) A questão da migração interna surge como objeto de reflexão da Sociologia no momento de acelerada industrialização e urbanização, processos concentrados no Centro-Sul do país e que deram lugar à formação de uma 'nova' classe operária nacional. Tais processos marcaram a sociedade brasileira nos anos de 1950 e 1960. Não sem razão, foram os sociólogos do trabalho industrial, em obras publicadas na década de 1960, os primeiros a tomar os migrantes nacionais como protagonistas importantes na sociedade urbano-industrial em formação. Na época, o desafio era compreender a emergência de um novo operariado que, diferentemente da "vanguarda operária" de origem europeia do início do século XX, tinha seus contingentes recrutados nas áreas rurais do país, principalmente do Nordeste, Minas Gerais e interior paulista". O mesmo destaca análises pioneiras sobre o tema na sociologia brasileira, tais como: Lopes (1964), Rodrigues (1970), Cardoso (1969) e Durham (1966, 1973).

20 Segundo Marandola Jr. e Dall Gallo (2010, apud Becker, Borges, 2015, p. 7) “(...) o apoio social fornece aos migrantes um espaço de segurança, novas aprendizagens e uma estratégia para a adaptação e sustentabilidade em um novo contexto cultural. Deste modo, pode atuar no amortecimento ao impacto das mudanças territoriais por permitir o incremento da autoestima, senso de eficácia, autoconfiança e possibilitar o senso de pertença que se estabelece a partir da identificação e cooperação entre os integrantes da rede social". 
"arrendatário deixar de produzir diretamente os meios da sua subsistência, o que o torna inteiramente dependente das relações com o mercado" e, por conseguinte, transforma-se a maneira como o tempo é percebido. Já não se deixa o 'tempo passar', a modernização da produção agrícola pressupõe também uma racionalização do tempo do trabalho, caracterizado por uma nova ética produtiva que avança mais e mais sobre o tempo festa, que também assume novos significados, inclusive para os sujeitos em questão.

Nesse sentido, por exemplo, o entrevistado rememora: “(...) o povo na roça tem poco prazo prá festá (...). O trabalho não dá mais muita oportunidade". De outro modo, o sofrimento psíquico experimentado pelo migrante em questão é alimentado não só pela perda de seu lugar de origem, mas também pela alteração do quadro de valores do mesmo, associada à transformação por ele sofrida.

Nesse processo, transformam-se representações sobre fenômenos naturais como a chuva e o sol, a noite e o dia, além do universo de relações individuais e/ou coletivas historicamente estabelecidas com tais fenômenos. Nessa perspectiva, convergimos com Thompson (1991, p. 49) quando esse analisa que: "(...) o tempo torna-se dinheiro - não passa, gasta-se". A festa, agora, tende a se transformar em objeto de consumo, atração de grandes vitrines. Transfiguradas as relações de produção do tempo do trabalho na roça, gradativamente, suas festas características tornam-se desencantadas e incorporadas pela lógica produtiva do mercado. Tal mudança - lamentada pelo migrante em questão - é também experimentada pelo mesmo como importante forma de elaboração da perda de seu lugar de origem, apresentando aspectos positivos no que concerne à sua dinâmica psíquica relativa ao seu processo de adaptação ao seu lugar de destino/residência, ou seja, amenizando o sofrimento causado por tudo aquilo que a necessidade de deslocamento impôs ao mesmo deixar para trás: parentes e amigos, paisagens e cheiros, gostos e sons etc.

As transformações das relações tradicionais de trabalho no campo em Goiás, a partir da década de 1950/1960, contribuíram também para um processo de (re)construção da percepção da festa por parte de tais atores sociais. Isso porque ela também está relacionada à fartura, à necessidade de um excedente mínimo, ainda que ocasionalmente, para ser viabilizada. E, no bojo de tais mudanças, a possibilidade desse tem decrescido com o processo de concentração de renda no campo.

Essa íntima relação entre festa e 'fartura' está também sugerida num fragmento da narrativa de Maria Ferreira de Souza. Ao falar do cotidiano de trabalho na roça, ela traz à tona imagens de sua família, da organização da mesma em função da necessidade de cuidar da lavoura, as articulações de tal instituição com os laços de vizinhança presentes nesse mundo. Isso acontece 
porque, na luta pela sobrevivência no campo, dos não proprietários e pequenos proprietários, cruzam-se várias temporalidades. Nesse meio, o trabalho tem um caráter familiar, comunitário e marcado por desigualdades de gênero muito naturalizadas. Ademais, suas temporalidades constitutivas são partes fundantes da constituição da subjetividade da migrante em questão, que rememoram o mesmo de forma marcada pelo duelo entre sentimentos associados à nostalgia e ao sofrimento. Observemos, pois, o que diz a depoente:

Olha o trabalho na roça, lá onde nóis morava (...). Quando era época de colheita a gente carregava caminhão, a gente capinava, a gente rancava feijão (...). Em geral, cozinhava, levava na roça, a gente servia comida na roça treis vezes ao dia, porque o peão não podia trabaiá com fome, e também a roça não podia sê perto da casa, por causa dos porco que agente soltava. A criação tinha que sê uma légua retirada, uma légua seria seis quilômetros. Cê vê, prá dá essa comida lá, seis quilômetros, treis vezes ao dia, era um pouco bem difícil né.

Nesse fragmento da narrativa, fica evidente a divisão das tarefas entre homens e mulheres, na qual participam determinantemente valores tradicionais no que tange aos papéis femininos e masculinos no campo. O mais importante para nosso objetivo de análise, entretanto, está em atentarmos para o modo como nesse fragmento da fala da mesma, esse tempo passado - do trabalho na "roça" - indica-nos não simplesmente a presença de um sentimento de nostalgia em tal dinâmica subjetiva, mas, sobretudo, um sentimento de nostalgia situado de forma confusa entre a desesperança, a desilusão e a melancolia (Bustamante, 2013). Sentimentos que talvez sejam mais compreensíveis se levarmos em conta que, nessa passagem, a casa, geralmente associada a um espaço do profundo e intenso enraizamento, pertencimento e reconhecimento, assume um significado que tem como pano de fundo memórias que emergem entrelaçadas a um passado de dificuldades e sofrimento.

\section{Conclusão}

Caminhando para a finalização desse artigo, concordando com Bustamante (2013) quando defende que toda migração é um corte na história de vida que coloca a imperiosa necessidade de (re)construir novos laços entre o passado, o presente e o futuro ${ }^{21}$; que trata-se de um fenômeno complexo marcado pela discriminação, desigualdades de gênero, racismo, machismo etc. Nesse sentido, entendemos que cada migrante na luta por moradia é um

\footnotetext{
${ }^{21}$ Essa dinâmica está presente no cotidiano de cada um dos três indivíduos referidos, que foram entrevistados em julho de 1998 (narrativas que agora revisitamos para produção desse artigo) e ocorre de forma recorrente, diversamente elaborada. Podemos citar como movimento, nesse sentido, o caso da depoente Maria de Jesus Rodrigues que, em 2013, lança segunda edição, na Universidade Federal de Goiás-UFG, de seu livro Retalhos de lembranças, no qual relembra, entre outras coisas, a ocupação da Fazenda Caveirinha, desenvolvendo assim o processo de (re)construção em questão.
} 
indivíduo em busca de uma síntese interna que ocorre através de redefinição cotidiana de seu velho mundo (paraíso perdido) num novo contexto enquanto forma de encontrar um sentido de continuidade.

E foi nessa linha, portanto, que exploramos os tempos do trabalho e das festas, da família e da casa, dos migrantes em tela, enquanto temporalidades permanentemente (re) elaboradas e atravessadas pelo sentimento de nostalgia enquanto afeto mediano entre o desejo e a realidade, o objeto fantasiado e o objeto real, a esperança e a ilusão. Sentimento que - não raramente - figurou nas narrativas, combinado a manifestações de sofrimento psíquico derivado da ausência-presença do lugar perdido e da necessidade de reconstruí-lo. De outra forma, cada narrativa estudada pode ser compreendida também como uma manifestação de resiliência que perpassa as motivações da partida do lugar de origem, as respostas aos desafios encontrados no deslocamento e as dificuldades de adaptação ao lugar de chegada/residência (ocupação Fazenda Caveirinha).

\section{Fontes Orais (Entrevistados):}

- Maria de Jesus Rodrigues - 46 anos à época da entrevista, ex-mutirante, migrante, membro da Associação de Moradores do Jardim Nova Esperança, criadora do grupo de teatro popular Alma Nova. Fragmento de entrevista que foi realizada em julho de 1998 e revisitado para a finalidade do artigo em tela;

- Maria Ferreira de Souza - 46 anos à época da entrevista, migrante, ex-mutirante, mãe de 06 filhos, natural de Pirenópolis-Goiás, ex-trabalhadora de fazendas do interior de Goiás e proveniente de uma família de 11 pessoas. Fragmento de entrevista que foi realizada em julho de 1998 e revisitado para a finalidade do artigo em tela;

- Olavo Novais Alves - 63 anos à época da entrevista, migrante e ex-mutirante, atualmente é vigia noturno e balconista. Fragmento de entrevista que foi realizada em julho de 1998 e revisitado para a finalidade do artigo em tela.

\section{Fontes Escritas (Jornais citados):}

- Cinco de Março: 26/06/1977;

- Folha de Goiás: 28/01/ 1977;

- Folha de Goiás: 07/11/1979;

- O Popular: 24/10/ 1979.

\section{Referências Bibliográficas}

ALBUQUERQUE JR., Durval Muniz de. Pedagogias da saudade: a formação histórica de consciências e sensibilidades saudosistas. A vida e o trabalho do poeta e professor português António Corrêa d'Oliveira. Revista História Hoje, v. 2, n. 4, p. 149-174, 2013. 
ALEXANDROFF, Marlene Coelho. O Papel das emoções na constituição do sujeito. Construção Psicopedagógica, v. 20, n. 20, p. 35-56, 2012.

ARAÚJO VIEIRA, Maria do Pilar; KHOURY, lara. Movimentos Sociais, documentação e história oral. Projeto História, v. 8, n. 9, p. 1-70, 1992.

ARIZA, Marina. Tonalidades emocionales en la experiência de la migración laboral, humillacíon y degración social. In: ARIZA, Marina (org.). Emociones, afectos y sociologia: dialogos desde la investigacion social y la interdisciplina. Mexico: Universidade Autonoma do Mexico-UNAM, Instituto de Investigaciones Sociales, 2016, p. 279-328.

BARRA E LOPES, Edmar Aparecido de. Ocupação Fazenda Caveirinha: arquipélago de memorias (Goiânia: 1970-1989). (Dissertação de mestrado) Pontifícia Universidade Católica de São Paulo-PUC/SP, São Paulo, 1999.

BARREIRO, Mateus Freitas; CARVALHO, Alonso Bezerra; FURLAN, Marta Regina. A arte e o afeto na inclusão escolar: potência e o pensamento não representative. Childhood \& Philosophy, v. 14, n. 30, p. 517-534, maio-ago 2018.

BECKER, Ana Paula Sesti; BORGES, Lucienne Martins. Dimensões psicossociais da imigração no contexto familiar. Bol. - Acad. Paul. Psicol., v. 35, n. 88, p. 124144, 2015.

BUSTAMANTE, Eduardo Llanos. Nostalgia y migración. Revista Psicoanálisis, v. 1, n. 11, p. 139-150, 2013.

CARDOSO, Fernando H. Proletariado no Brasil: situação e comportamento social. In: CARDOSO, Fernando H. Mudanças Sociais na América Latina. São Paulo: Difusão Europeia de Livro, 1969.

CERTEAU, Michel de. A invenção do cotidiano: 1. Artes de Fazer. Petrópolis: Vozes, 1994.

CHAVES, Elza Guedes. De Invasor a Posseiro: Estado-Igreja e a Luta pela Terra Urbana. (Dissertação de Mestrado) Universidade Federal da Paraíba, João Pessoa, 1985.

DA COSTA, Samira Lima; DE CASTRO E SILVA, Carlos Roberto. Afeto, memória, luta, participação e sentidos de comunidade. Pesquisas e Práticas Psicossociais, v. 2, n. 10, p. 283-291, 2015.

DA COSTA, Samira Lima; MACIEL, Tania Maria de Freitas Barros. Os sentidos da comunidade: a memória de bairro e suas construções intergeracionais em estudos de comunidade. Arq. bras. psicol., v. 61 n. 1, p. 60-72, 2009.

DA MATA, Sérgio et alii (orgs.). Tempo presente \& usos do passado. Rio de Janeiro: Editora FGV, 2012.

DAS, Veena. Fronteiras, violência e o trabalho do tempo: alguns temas wittgensteinianos. Revista Brasileira de Ciências Sociais, São Paulo, v. 14, n. 40, p. 31-42, 1999.

DAS, Veena. O ato de testemunhar: violência, gênero e subjetividade. Cadernos Pagu, Campinas, n. 37, p. 9-41, dez. 2011. 
DELEUZE, Gilles. Aula sobre Spinoza. 1978. Disponível em: <http://www. webdeleuze.com/php/texte. Php>. Acesso em: 22.08.2018.

DELEUZE, Gilles. Espinosa: filosofia prática. São Paulo: Escuta, 2002.

DURHAM, Eunice. Migração, trabalho e família: aspectos do processo de integração do trabalhador de origem rural à sociedade urbano-industrial. (Tese de Doutorado) Pós-Graduação em Sociologia da Faculdade de Filosofia, Letras e Ciências Humanas da Universidade de São Paulo (USP-SP), São Paulo, 1966.

DURHAM, Eunice. A caminho da cidade: a vida rural e a migração para São Paulo. São Paulo-SP: Perspectiva, 1973.

FERREIRA, Marieta de Moraes. Demandas sociais e história do tempo presente. In: VARELLA, Flávia; MOLLO, Helena Miranda; PEREIRA, Mateus Henrique de Faria; DA MATTA, Sérgio. Tempo presente e usos do passado. Rio de Janeiro: FGV Editora, 2012, p. 101-124.

GLICK-SCHILLER, Nina. Nuevas y Viejas cuestiones sobre localidad: teorizar la migración transnacional en un mundo neoliberal. In: SOLÉ, Carlota; PARELLA, Sonia; CAVALCANTI, Leonardo (coords.). Nuevos Retos del Transnacionalismo en el Estudio de las Migraciones. Madrid: Ministerio de Trabajo e InmigraciónGrafo S.A, 2008, p. 21-46.

GOHN, Maria da Glória. Teoria dos movimentos sociais: paradigmas clássicos e contemporâneos. São Paulo: Edições Loyola, 1997.

GOMES, Lucius Fabius Ben Jah Jacob. Uma história urbana da vida cotidiana da autoconstrução do Jardim Nova Esperança em Goiânia (1979-1983). (Dissertação de Mestrado) Universidade Federal de Goiás-UFG, Goiânia, 2019.

GONÇALVES, Larissa Silva. Trajetórias do imaginar: migrações de afetos, memórias e sentidos. (Tese de doutorado) Programa de Pós-Graduação em Sociedade e Cultura na Amazônia, Universidade Federal do Amazonas - UFAM, Amazonas, 2018.

GOODWIN, Jeff; JASPER, James; POLLETTA, Francesca (orgs.). Passionate politics: emotions and social movements. Chicago: University of Chicago Press, 2001.

HALBWACHS, Maurice. Los marcos sociales de la memoria. Barcelona: Anthropos, 2004.

HIRAI, Shinji. La nostalgia. Emociones y significados en la migración trasnacional. Nueva Antropología, n. 81, v. 27, p. 77-94, 2014.

HOGGETT, Paul; THOMPSON, Simon (orgs.). Politics and the Emotions: the affective turn in contemporary political studies. New York: Continuum, 2012.

LARA, Itzel Hernández. Migración e afectividad a distancia. Escenarios emocionales relacionados com la dinámica familiar transnacional en el context de la migración oaxaqueña hacia los Estados Unidos. In: ARIZA, Marina (org.). Emociones, afectos y sociologia: dialogos desde la investigacion social y la interdisciplina. Mexico: Universidade Autonoma do Mexico - UNAM, Instituto de Investigaciones Sociales, 2016, p. 109-149. 
LOPES, Juarez B. R. Sociedade Industrial no Brasil. São Paulo: Difel, 1964.

LUCENA, Célia P. de T. Refazendo trajetórias: memórias de migrantes mineiros em São Paulo (Jardim Barbacena, 1960-1995). (Tese de Doutorado) Pontifícia Universidade Católica de São de Paulo (PUC-SP), São Paulo, 1997.

LUTZ, Catherine; WHITE, Geoffrey M. The anthropology of emotions. Annual Review of Anthropology, Palo Alto, v. 15, n. 16, p. 297-325, fev. 1986.

MARANDOLA JR., Eduardo; DAL GALLO, Priscila Marchiori. Ser migrante: Implicações territoriais e existenciais da migração. Revista Brasileira Estudos Populacionais, v. 27, n. 2, p. 407-424, 2010.

MARTINS, José de S. Capitalismo e tradicionalismo: estudos sobre as contradições da sociedade agrária no Brasil. São Paulo-SP: Pioneira, 1975.

MCMILLAN, David W.; CHAVIS, David M. Sense of Community: A Definition and Theory. Journal of Community Psychology, v. 14, n. 1, p. 6-23, 1986.

MONTERO, Maritza. Introducción a La psicología comunitaria: desarrollo, conceptos y procesos. Buenos Aires: Paidós, 2007.

PORTELLI, Alessandro. Tentando aprender um pouquinho: algumas reflexões sobre a ética na História Oral. Revista PROJETO HISTÓRIA, v. 1, n. 15, p. 13-49, 1997.

REZENDE, Cláudia B.; COELHO, Maria C. Antropologia das emoções. Rio de Janeiro: Ed. FGV, 2010.

RODRIGUES, Leôncio M. Industrialização e atitudes operárias. São Paulo-SP: Brasiliense, 1970.

RODRIGUES, Maria de Jesus. Retalhos de lembranças. Editora Kelps: Goiânia, 2013.

SANTANA, Charles A. Fartura e ventura camponesas: trabalho, cotidiano e migrações (Bahia: 1950-1980). São Paulo-SP: Anna Blume, 1998.

SAWAIA, Bader B. O sofrimento ético-político como categoria de análise da dialética exclusão/inclusão. In: SAWAIA, Bader B. As artimanhas da exclusão: uma análise ético-psicossocial. São Paulo: Vozes, 2002.

SCOTT, Joan W. A invisibilidade da experiência. Revista Projeto História, v. 1, n. 16, p. 1-29, 1998.

SILVA, Uvanderson Vitor da. Velhos caminhos, novos destinos: migrante nordestino na região metropolitana de São Paulo. (Dissertação de mestrado) Programa de Pós-Graduação em Sociologia da Faculdade de Filosofia, Letras e Ciências Humanas da Universidade de São Paulo (USP-SP), São Paulo, 2008.

SOUROUJON, Gastón. Reflexiones en torno a la relación entre memoria, identidad e imaginación. Andamios, v. 8, n. 17, p. 253-257, 2011.

THOMPSON, Edward P. Costumes em comum. Estudos sobre a cultura popular tradicional. São Paulo: Companhia das Letras,1998.

THOMPSON, Edward P. O Tempo, a disciplina do trabalho e o capitalismo industrial. In: SILVA, Tomaz T. (org.). Trabalho, educação e prática social: por uma teoria da formação humana. Porto Alegre: Artes Médicas, 1991. 
THOMPSON, Paul. A voz do passado: história oral. Rio de Janeiro: Paz e Terra, 1992.

THOMPSON, Edward P. A miséria da teoria: ou um planetário de erros. Rio de Janeiro: Zahar, 1981.

THOMSON, Alistair. Recompondo a memória: questões sobre a relação, a história oral e as memórias. Revista Projeto História, v. 1, n. 15, p. 1-33, 1997.

THOMSON, Alistair. Quando a memória é um campo de batalha: envolvimentos pessoais e políticos com o passado do exército nacional. Revista Projeto História, São Paulo, n. 16, p. 277-96, fev. 1998.

TÖNNIES, Ferdinand. Community and society: Gemeinschaft und Gesellschaft. Michigan: The Michigan State University Press, 1957.

TOURTIER-BONAZZI, Chantal de. Arquivos: propostas metodológicas. In: FERREIRA, Marieta M.; AMADO, Janaina (orgs.). Usos e abusos da história oral. Rio de Janeiro: Fundação Getúlio Vargas, 1998.

WILLIAMS, Raymond. Marxism and literature. Oxford: Oxford University Press, 1977. 